\title{
Study on the risk level of food production enterprise based on TOPSIS method
}

\author{
Tzu-Chia CHEN ${ }^{1 *}$ D, Shu-Yan YU ${ }^{1}$
}

\begin{abstract}
International food trade necessitates the existence of effective anti-tampering systems to protect against food toxins, thus making this kind of contamination difficult to get around. Due to a short growing season, fresh fruits and vegetables are easily damaged by spoilage and can lose much of their value. Being transported and stored is dangerous. Due to these risks, food prices will continue to rise for fresh produce. They are in such short supply that the fresh products will have a dramatic and urgent need for the supply chain. The journey to food and nutrition protection starts with a thorough examination of the problems that must be addressed in order to establish appropriate solutions. As a result, decision-making is defined as the process of selecting the best option from a set of options. The Technique for Order Preference by Similarity to Ideal Solution (TOPSIS) continues to work well among various multi-criteria decision-making models. Based on the TOPSIS method, this study focuses on the risk level of a food production enterprise.
\end{abstract}

Keywords: food trade; fresh products; supply chain; decision-making.

Practical Application: Risk level of food production enterprise.

\section{Introduction}

The change from the conventional supply chain of fresh agricultural products to the new agricultural product supply chain is crucial for fresh agricultural products in China. The use of advanced technologies and a new supply chain operating mode increases the value of the fresh agricultural commodity supply chain while lowering conventional supply chain danger (Zhang et al., 2021). Simultaneously, it adds a new threat. The most basic consumer commodities in people's lives are fresh farm items. Nevertheless, food-safety incidents have been more common in recent years. Food safety was granted further priority by the public. As a result of these reasons, the fresh agricultural commodity supply chain has received increased interest. The fresh agricultural commodity circulation supply chain was in poor shape. The supply chain's risk-resistance capabilities were also lacking. Farm products, on the other side, seem to have a uniqueness. During the circulation phase, a large number of agricultural goods needed to be disposed of. Rural infrastructure, on the other hand, was not up to par. It was hard to span the whole distribution network (Yang et al., 2020; Zandi et al., 2020). This culminated in a higher cost of circulation. These conditions posed a significant threat to the supply chain for fresh farm goods. As a result, determining the fresh agricultural goods supply chain danger was critical.

The food industry is under pressure to improve food safety and quality by addressing risk management and the ability to respond quickly to threats by incorporating traceability. The traceability system is defined as a document-based record-keeping system that determines the operations that lead to product production and sale. This article reports on a study of traceability systems and methods for achieving various business objectives.
The TOPSIS method ranks options using a multi-criteria decision-making (MADM) approach. The terms "ideal solution" and "similarity to the ideal solution" are used in this method (Guo, 2020; Liu et al., 2020; Rostamzadeh et al., 2018). The ideal solution, as the name suggests, is the best solution in every way, which does not exist in practice, and it tries to get closer to it. The distance between a design (or option) and an ideal and counter-ideal solution is measured to determine its similarity to the ideal and counter-ideal solution. The options are then ranked based on the distance from the counter-ideal solution to the total distance between the ideal and counter-ideal solutions. The acronym TOPSIS stands for Technique for Order of Preference by Similarity to Ideal Solution and is derived from the initials of the phrase (Certa et al., 2018; Chang et al., 2019).

A MADM problem with $m$ options is viewed by TOPSIS as a geometric system with $\mathrm{m}$ points in the next $\mathrm{n}$ space. The method is based on the idea that the alternative should be the closest to the positive-ideal solution and the furthest from the negative-ideal solution (Korkmaz \& Gurer, 2018; Silva et al., 2018). TOPSIS uses the terms "similarity with a positive-ideal solution" and "avoidance of a negative-ideal solution" to describe an indicator. Then select the alternative method that comes closest to the positive-ideal solution (Al Zubayer et al., 2019; Ocampo et al., 2020; Ocampo, 2019; Ortiz-Barrios et al., 2020).

If an option appears to be the best choice, it has a higher degree. We try to approximate the ideal solution, which is practically the best in every aspect that does not exist. Essentially, we consider the distance between a design (or option) and an ideal and non-ideal solution to determine its similarity to an 
ideal and non-ideal level (Akcan \& Taş, 2019; Jędrkiewicz et al., 2018; Konuk, 2018).

The following are the method's underlying assumptions:

- Each criterion's desirability should be consistent, increasing or decreasing. In other words, increasing the value of a criterion's desirability, whether qualitative or quantitative, increases its desirability. In order for the best available value to be considered ideal and the worst value to be considered counter-ideal, criteria must be uniformly decreasing or increasing;

- Criteria should be created in such a way that they are self-contained (being independent means the absence of internal relations);

- Because the exchange rate between criteria is usually a number other than one, the Euclidean distance is used to calculate the distance between the ideal and anti-ideal solutions.

The TOPSIS method has a number of advantages (Selim et al., 2016; Suder \& Kahraman, 2018; Xue et al., 2008; Zolfani et al., 2012):

- If there are positive and negative criteria, decisions can be made (even together in one issue). Positive criteria have a profit component, such as product quality, while negative criteria have a loss component, such as hard work;

- A large number of criteria can be considered when determining the best option, but the AHP or ANP methods have practical and inherent limitations in this area;

- This method is simple, fast, and responsive to a wide range of options and criteria;

- Qualitative criteria can be easily quantified in the TOPSIS method, and decisions can be made based on both qualitative and quantitative criteria;

- The system's output is numerical, and in addition to determining the superior option, it also ranks the other options numerically. This numerical value is the relative proximity, which expresses the method's solid foundation;

- The mathematical foundations of the TOPSIS method are solid. This method is used to calculate distances. TOPSIS chooses the option with the greatest distance from the worst option and the shortest distance from the best option as the optimal option, and it is superior to other MADM methods because of this and its mathematical foundation;

- Another advantage of the TOPSIS method over some MADM methods is that it is a compensatory method. That is, in this method, the weight of all options and criteria is considered in the decision, and no weight is ignored.

This study explored certain variables which impacted fresh agricultural product supply chain danger and suggested fresh agricultural product supply chain risk assessment indexes. This study states an updated TOPSIS approach in response to the issue of whether the TOPSIS technique's weights are determined via subjective factors. Eventually, the tool is used to determine the fresh agricultural goods supply chain danger.

\section{Materials and methods}

Each day, all humans are exposed to a variety of risks and threats, including those linked to the food they eat. Foodborne hazards can and do inflict injuries and damage to human health. Per year, millions of people around the world get food poisoning. Uncontrolled and abusive use of industrial pesticides, environmental pollution, usage of unregulated pesticides, poor product safety management, and handling procedures during food production and other food-based violations may all lead to the implementation of hazards or the inability to mitigate hazards relevant to food. The impact of food-related hazards on public health, the relevance and exponential development of global food trading, and customer desire for a healthy food supply render food-related risk analysis more relevant than ever before (Samvedi et al., 2013).

Consumers are worried about food contaminants, agricultural and veterinary pesticide pollutants, viral, chemical, and physical contamination, radionuclide radiation, and unsafe and inappropriate food processing and packaging processes, any of which can introduce hazards to food at any stage in the food chain, from primary production to the end consumer. Consumers in developed nations pose the most concerns on these topics, but developments in global connectivity have piqued market interest in these issues all over the planet (Chang, 2015; Nazam et al., 2015).

The TOPSIS technique, or prioritization based on similarity to the ideal solution, is a multi-criteria decision-making method first introduced by (Lai et al., 1994). This technique can be used to rank and compare various options in order to choose the best one, as well as to determine the distances between options and group them together. One of the benefits of this method is that the criteria or indicators used for comparison can have different units of measurement and can be both negative and positive. In other words, in this technique, negative and positive indicators can be combined.

The best option or solution, according to this method, is the one that is closest to the ideal solution or option while being the furthest away from the non-ideal solution. The ideal solution is the one that maximizes profit while minimizing cost, whereas the non-ideal solution is the one that maximizes cost while minimizing profit. In a nutshell, the ideal solution is derived from the sum of each criterion's maximum values, whereas the non-ideal solution is derived from the sum of each criterion's lowest values (Behzadian et al., 2012). There are six steps to this technique:

Step 1. Create a decision matrix;

Step 2. Make the decision matrix normal;

Step 3. Find the best ideal solution and the worst ideal solution; 
Step 4. Calculate how far each option is from the positive and negative ideals;

Step 5. For each option, calculate the proximity coefficient;

Step 6. Prioritize the options based on their proximity.

The TOPSIS solution technique is depicted as a flowchart (Figure 1).

The supply chain vulnerability of fresh agricultural goods is influenced by a variety of factors. We appeal to literature at home and abroad and correlate with the characteristics of the supply chain risk of horticultural products on the basis of defining the supply chain risk of fresh agricultural products, the method theory, viability principle, and contrast concept. Following that, we establish a fresh agricultural commodity supply chain risk assessment scheme. The following is the fresh agricultural goods supply chain risk management framework (Table 1).

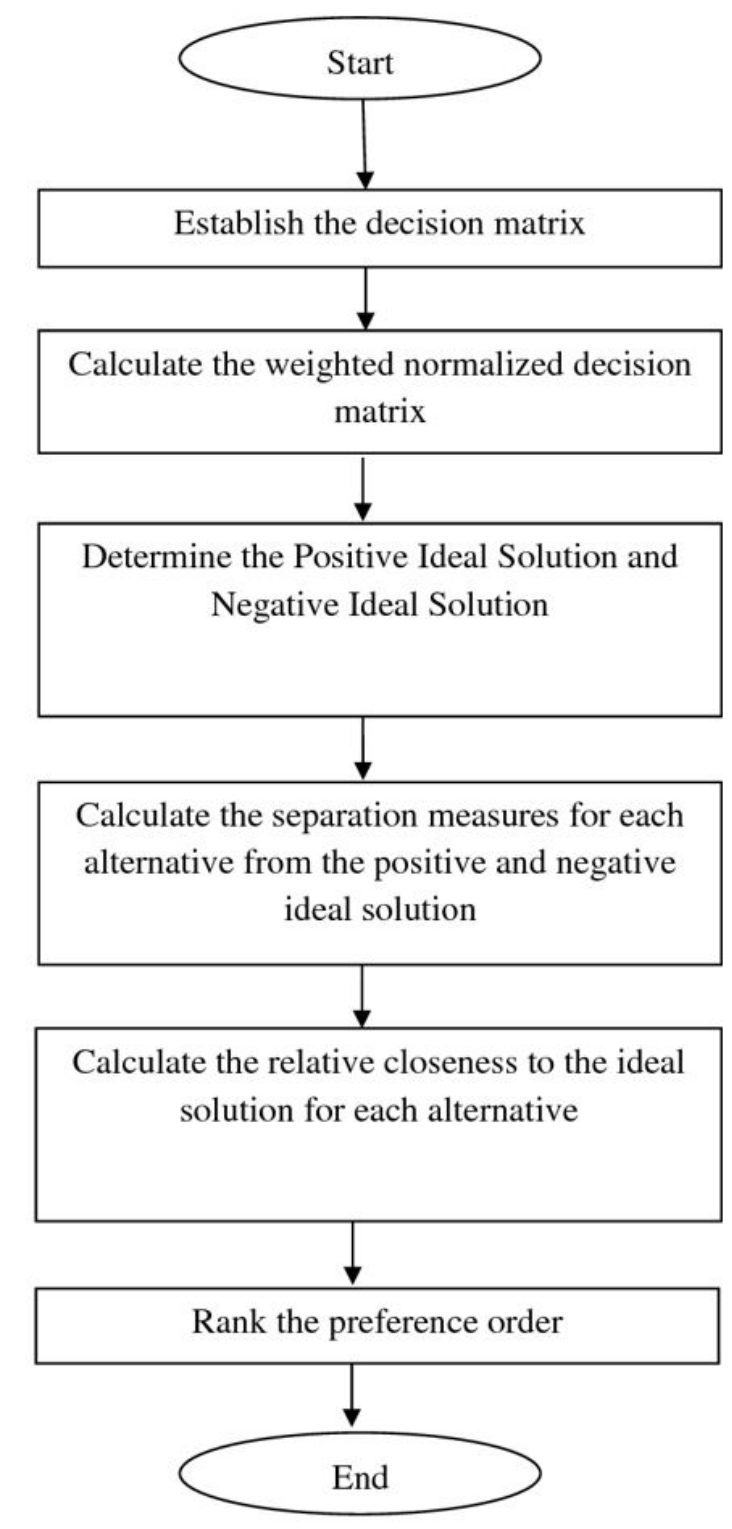

Figure 1. TOPSIS flowchart.

\section{Results and discussion}

Food will always face numerous risks throughout the food supply chain, from farm to fork, which will result in numerous issues for subsequent processes and end consumers. We all eat fruits, vegetables, dairy products, meat, bread, and other foods on a daily basis, and the health and safety of these foods are critical to our well-being. Have you ever considered the dangers of eating foods that are unhealthy or appear to be unhealthy? Are you aware of the dangers of toxins, pesticides, and some preservatives, as well as pathogenic microbes, in the food you consume on a daily basis? Which institution or organization is in charge of ensuring food safety and health?

Answering the above questions necessitates a thorough examination of the risks and dangers that threaten food safety and health. Many countries around the world are working to develop a system for managing food safety risks in order to provide safe and nutritious food. Instructions and rules have been established for this purpose, indicating how and when to use scientific expertise in the risk analysis process. One of the major challenges in both developed and developing countries is ensuring food safety in order to maintain public health and economic development. In recent decades, there have been numerous advancements in food safety systems.

The risk analysis process, which is based entirely on science and comprehensive risk analysis, is one of these modern systems for food safety. This method, as its name implies, is a set of measures that, when fully implemented and realized, include a developed system of expertise and skills in the field of problem management and food safety.

\subsection{Risk analysis framework}

A method for gathering, analyzing, and systematically evaluating scientific and non-scientific data on chemical, biological, and physical hazards in food to determine the best risk management strategy. Risk analysis is divided into three parts, according to the Codex guidelines: risk assessment, risk management, and risk communication. New data or information, as well as changes in the content of food problems, should be reviewed as needed by risk analysis, which is a dynamic and highly repetitive interaction program. To conduct risk analysis successfully, countries must have a well-functioning food safety system in which all stakeholders, including government, industry, academia, and consumers, are involved.

Risk analysis should be based on all available scientific evidence, information, costs, cultural and environmental factors, and other factors that are gathered, as well as scientific principles to the extent possible.

\subsection{Food safety risk analysis system components}

It is necessary to understand the components of this process in order to be aware of it. The following are the components:

- Risk evaluation: This value is derived from a scientific procedure that includes the following elements: 1- Identifying the danger, 2- Dangerous properties, 3- Assessment and exposure, 4 - Characteristics of risk; 
Table 1. Fresh agricultural sector supply chain risk management framework.

\begin{tabular}{lll}
\hline \multicolumn{1}{c}{ First-order index } & \multicolumn{1}{c}{ Second-order index } & \multicolumn{1}{c}{ Third-order index } \\
\hline $\begin{array}{l}\text { Supply chain risk evaluation } \\
\text { system of the }\end{array}$ & Internal risk & Risk in choosing suppliers and dealers \\
agricultural products & Quality risk of the fresh agricultural products \\
fresh & Technical risk \\
& & Risk of deterioration for the fresh agricultural products \\
& Risk management decision \\
& Quality of supply chain risk \\
& & Structure of the supply chain risk \\
& Credit risks \\
& Market environment risk \\
& Demand fluctuation risk \\
& Supply fluctuation risk \\
& Natural risk \\
& Policy risk \\
& Cooperation risk \\
& Transportation risk \\
& Distribution of risk \\
& Inventory risk \\
& Information transfer risk \\
& & Information security risk \\
\hline
\end{tabular}

- Risk management: This parameter encompasses the process of evaluating various guidelines, such as risk assessment and other factors affecting consumer health and promoting fair trade, as well as the selection of effective prevention and control methods to ensure food safety, if necessary;

- Communication is a high-risk situation: Risk-related individuals, such as risk managers, consumers, industry, academia, and other stakeholders, exchange information and opinions about risk, risk-related factors, and risk characteristics during the risk analysis process. It entails a multifaceted exchange of information and perspectives on risk-related factors and risk perception among decision-makers as part of the risk analysis process, and it serves as the foundation for risk management decision-making. This parameter encompasses the multifaceted exchange of information and perspectives on risk-related factors and risk perception among decision-makers, as well as the basis for risk management decision-making.

Although the components of risk analysis are depicted separately above, they are in reality completely dependent on one another and, in some cases, overlap. In the field of food risk and health analysis, there is a constant battle between risk managers and risk assessors over the risk at hand. It's worth noting that the FDA (Food and Drug Administration) and the USDA (United States Department of Agriculture) are two separate agencies within the US Department of Health and Human Services. Both organizations are in charge of food safety, but their situations are distinct.

The USDA is in charge of risk assessment for agricultural products, while the FDA is in charge of risk assessment for food, food additives, and medical devices. It's also worth noting that the European Food Safety Authority (EFSA) is in charge of EU risk assessment in food safety matters. Risk assessment and risk management are completely separate in the European food safety system. EFSA investigates risk cases in a scientific manner before referring them to the European Union for standardization and legislation.

\subsection{Improved TOPSIS method}

A mathematical research approach is the TOPSIS method. The procedure uses the spacing that is well removed from the optimal negative situation and approaches the optimal situation as the decision parameter in order to create the optimal situation and the negative ideal solution of the objective function. It makes the final judgment after ordering the assessment items. The TOPSIS method's weights are heavily influenced by the views of specialists. The degree of professional expertise and practice is a consideration. Furthermore, professional tastes are easily affected, and it has a large subjective component. As a consequence, we integrate the TOPSIS approach with the entropy method to boost it. The modified TOPSIS system is then presented. The approach will allow the decision-making process more standardized by reducing individual considerations. The improved TOPSIS approach has the following judgment steps:

1) For each evaluation index, we provide the index value based on the data details provided by the evaluation object. The original matrix is then listed;

2) To standardize the decision matrix and obtain the normalized matrix, we use the vector normalization process;

3) We pre-process the assessment indexes in accordance with the index's characteristics. It advances to the next level if the appraisal index is optimistic. We would reverse the evaluation index to the positive index if it is negative; 
Table 2. Weight of index.

\begin{tabular}{lcc}
\hline \multicolumn{1}{c}{ Third order index } & Weight & Second order index \\
\hline Risk in choosing suppliers and dealers & 0.12 & Internal risk \\
Quality risk of the fresh agricultural products & 0.23 & \\
Technical risk & 0.15 & \\
Risk of deterioration for the fresh agricultural products & 0.23 & \\
Risk management decision & 0.17 & \\
Quality of supply chain risk & 0.05 & External risk \\
Structure of the supply chain risk & 0.05 & \\
Credit risks & 0.08 & \\
Market environment risk & 0.11 & \\
Demand fluctuation risk & 0.26 & \\
Supply fluctuation risk & 0.26 & \\
Natural risk & 0.10 & \\
Policy risk & 0.10 & Logistics risk \\
Cooperation risk & 0.09 & \\
Transportation risk & 0.33 & Information risk \\
Distribution of risk & 0.33 & 0.28 \\
Inventory risk & 0.33 & 0.5 \\
Information transfer risk & 0.5 & \\
Information security risk & & \\
\hline
\end{tabular}

4) We use the standardized therapy approach to provide a non-dimensional treatment for the evaluation index in order to minimize the disparity between measurements;

5) We should convert the index value after the non-dimensional transformation to remove the partial negative value;

6) The index proportion is determined;

7) When measuring the entropy value, the lower the variations between the index values, the higher the entropy value;

8) Determine the index's entropy value;

9) Each indices' weight is calculated;

10) The weighted normalized matrix is being constructed. We should take into account the weights of each evaluation index since their value varies. We convert the normalized data to a weighted normalized matrix by weighting it;

11) Identifying the optimistic and negative optimal solutions for each of the measured object's indices;

12) Measuring the Euclidean distance between the test object and the positive and negative ideal solutions;

13) Measuring the difference between two points. The degree of proximity between the test object and the positive and negative optimal solutions.

The assessment object is sorted according to its relative approach degree. We then use enhanced TOPSIS approach to test the supply chain danger of fresh agricultural goods in 4 separate groups to check the method's validity and reliability. The weight of the assessment index can be accessed (Table 2).

The lengths from the positive to the negative are, (Equation 1) $d_{1}^{+}=0.0786, d_{1}^{-}=0.1348, d_{2}^{+}=0.1211, d_{2}^{-}=0.1105$

$d_{3}^{+}=0.1260, d_{3}^{-}=0.1088, d_{4}^{+}=0.0971, d_{4}^{-}=0.1301$

The degree of relative approach is, (Equation 2)

$C_{1}=0.6317, C_{2}=0.4772, C_{3}=0.4634, C_{4}=0.5726$

$C_{1}<C_{4}<C_{2}<C_{3}$

\section{Conclusion}

New organic goods have more strict supply chain specifications owing to their uniqueness. As a result, the fresh agricultural commodity supply chain is subject to greater danger than the general supply chain. Assessing the fresh agricultural supply chain danger will help managers make better decisions and avoid risk. When measuring the weight, the TOPSIS approach relies on expert opinion. As a consequence, the test outcome is highly arbitrary, and objectivity is lacking. The improved TOPSIS approach is proposed in this article, which incorporates the improved entropy and TOPSIS methods. The approach is then used to determine the fresh agricultural commodity supply chain danger in this article. The outcomes of the assessment show that the method is successful.

The TOPSIS methodology is used to quantify the complex quantitative national food and security index, which is made up of nine distinct measures that assess these food and nutrition security motors. It is the first index to look at food and nutrition security holistically through the four nationally recognized dimensions. Furthermore, the research goes past food and nutrition stability by addressing the variables that impact the food system's instability and durability, as well as food and nutrition vulnerability. This is a modern TOPSIS program that evaluates a country's food system and identifies the most significant obstacles and aptitudes in achieving the most 
critical target of food and nutrition stability. While seeking to understand whether the food system has changed or degraded through time, we used this quantitative approach to uncover the evolving pattern in food and nutrition defense. This strategy aims to assist decision-makers in developing the appropriate frameworks that allow food systems to function efficiently in order to have a policy impact.

\section{References}

Akcan, S., \& Taş, M. A. (2019). Green supplier evaluation with SWARATOPSIS integrated method to reduce ecological risk factors. Environmental Monitoring and Assessment, 191(12), 736. http:// dx.doi.org/10.1007/s10661-019-7884-3. PMid:31707512.

Al Zubayer, M. A., Ali, S. M., \& Kabir, G. (2019). Analysis of supply chain risk in the ceramic industry using the TOPSIS method under a fuzzy environment. Journal of Modelling in Management, 14(3), 792-815. http://dx.doi.org/10.1108/JM2-06-2018-0081.

Behzadian, M., Otaghsara, S. K., Yazdani, M., \& Ignatius, J. (2012). A state-of the-art survey of TOPSIS applications. Expert Systems with Applications, 39(17), 13051-13069. http://dx.doi.org/10.1016/j. eswa.2012.05.056.

Certa, A., Enea, M., Galante, G. M., Izquierdo, J., \& Fata, C. M. L. (2018). Food safety risk analysis from the producers' perspective: prioritisation of production process stages by HACCP and TOPSIS. International Journal of Management and Decision Making, 17(4), 396-414. http://dx.doi.org/10.1504/IJMDM.2018.095720.

Chang, K.-H. (2015). A novel general risk assessment method using the soft TOPSIS approach. Journal of Industrial and Production Engineering, 32(6), 408-421. http://dx.doi.org/10.1080/21681015. 2015.1070375 .

Chang, T.-W., Lo, H.-W., Chen, K.-Y., \& Liou, J. J. (2019). A novel FMEA model based on rough BWM and rough TOPSIS-AL for risk assessment. Mathematics, 7(10), 874. http://dx.doi.org/10.3390/ math7100874.

Guo, Z. (2020). Evaluation of financial ability of port listed companies based on entropy weight TOPSIS model. Journal of Coastal Research, 103(sp1), 182-185. http://dx.doi.org/10.2112/SI103-039.1.

Jędrkiewicz, R., Tsakovski, S., Lavenu, A., Namieśnik, J., \& Tobiszewski, M. (2018). Simultaneous grouping and ranking with combination of SOM and TOPSIS for selection of preferable analytical procedure for furan determination in food. Talanta, 178, 928-933. http://dx.doi. org/10.1016/j.talanta.2017.10.044. PMid:29136918.

Konuk, F. (2018). Financial and performance analysis of food companies: application of TOPSIS and DEA. Manas Sosyal Araştırmalar Dergisi, 7(3), 381-390.

Korkmaz, M., \& Gurer, D. (2018). Financial performance evaluation of forest village cooperatives: a multi-criteria TOPSIS approach. Cerne, 24(3), 280-287. http://dx.doi.org/10.1590/01047760201824032532.

Lai, Y.-J., Liu, T.-Y., \& Hwang, C.-L. (1994). Topsis for MODM. European Journal of Operational Research, 76(3), 486-500. http:// dx.doi.org/10.1016/0377-2217(94)90282-8.

Liu, W., Gao, Y., Yan, T., \& Cao, L. (2020). Risk evaluation of project bidding based on TOPSIS model. In International Conference on Application of Intelligent Systems in Multi-Modal Information Analytics (pp. 150-157). Cham: Springer.

Nazam, M., Xu, J., Tao, Z., Ahmad, J., \& Hashim, M. (2015). A fuzzy AHP-TOPSIS framework for the risk assessment of green supply chain implementation in the textile industry. International Journal of Supply and Operations Management, 2(1), 548-568.

Ocampo, L. A. (2019). Applying fuzzy AHP-TOPSIS technique in identifying the content strategy of sustainable manufacturing for food production. Environment, Development and Sustainability, 21(5), 2225-2251. http://dx.doi.org/10.1007/s10668-018-0129-8.

Ocampo, L., Deiparine, C. B., \& Go, A. L. (2020). Mapping strategy to best practices for sustainable food manufacturing using fuzzy

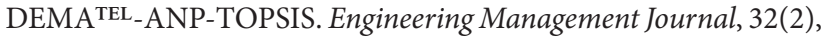
130-150. http://dx.doi.org/10.1080/10429247.2020.1733379.

Ortiz-Barrios, M., Miranda-De la Hoz, C., López-Meza, P., Petrillo, A., \& De Felice, F. (2020). A case of food supply chain management with AHP, DEMA ${ }^{\mathrm{TEL}}$, and TOPSIS. Journal of Multi-Criteria Decision Analysis, 27(1-2), 104-128. http://dx.doi.org/10.1002/mcda.1693.

Rostamzadeh, R., Ghorabaee, M. K., Govindan, K., Esmaeili, A., \& Nobar, H. B. K. (2018). Evaluation of sustainable supply chain risk management using an integrated fuzzy TOPSIS-CRITIC approach. Journal of Cleaner Production, 175, 651-669. http://dx.doi.org/10.1016/j. jclepro.2017.12.071.

Samvedi, A., Jain, V., \& Chan, F. T. (2013). Quantifying risks in a supply chain through integration of fuzzy AHP and fuzzy TOPSIS. International Journal of Production Research, 51(8), 2433-2442. http://dx.doi.org/10.1080/00207543.2012.741330.

Selim, H., Yunusoglu, M. G., \& Yılmaz Balaman, Ş. (2016). A dynamic maintenance planning framework based on fuzzy TOPSIS and FMEA: Application in an international food company. Quality and Reliability Engineering International, 32(3), 795-804. http://dx.doi. org/10.1002/qre.1791.

Silva, M., Gomes, C. F. S., \& Costa Junior, C. L. D. (2018). A hybrid multicriteria methodology Topsis-Macbeth-2n applied in the ordering of technology transfer offices. Pesquisa Operacional, 38(3), 413-439. http://dx.doi.org/10.1590/0101-7438.2018.038.03.0413.

Suder, A., \& Kahraman, C. (2018). Multiattribute evaluation of organic and inorganic agricultural food investments using fuzzy TOPSIS Technological and Economic Development of Economy, 24(3), 844858. http://dx.doi.org/10.3846/20294913.2016.1216905.

Xue, D., Zhao, Q., \& Guo, X. (2008). TOPSIS method for evaluation customer service satisfaction to fast food industry. In 2008 IEEE International Conference on Service Operations and Logistics, and Informatics (pp. 920-925). New York: IEEE.

Yang, T., Zhang, Q., Wan, X., Li, X., Wang, Y., \& Wang, W. (2020). Comprehensive ecological risk assessment for semi-arid basin based on conceptual model of risk response and improved TOPSIS model-a case study of Wei River Basin, China. The Science of the Total Environment, 719, 137502. http://dx.doi.org/10.1016/j. scitotenv.2020.137502. PMid:32126408.

Zandi, P., Rahmani, M., Khanian, M., \& Mosavi, A. (2020). Agricultural risk management using fuzzy TOPSIS Analytical Hierarchy Process (AHP) and Failure Mode and Effects Analysis (FMEA). Agriculture, 10(11), 504. http://dx.doi.org/10.3390/agriculture10110504.

Zhang, X., Chen, M., Guo, K., Liu, Y., Liu, Y., Cai, W., Wu, H., Chen, Z., Chen, Y., \& Zhang, J. (2021). Regional land eco-security evaluation for the mining city of Daye in China using the GIS-based grey TOPSIS method. Land, 10(2), 118. http://dx.doi.org/10.3390/land10020118.

Zolfani, S. H., Rezaeiniya, N., Pourhossein, M., \& Zavadskas, K. (2012). Decision making on advertisement strategy selection based on life cycle of products by applying FAHP and TOPSIS GREY: growth stage perspective; a case about food industry in Iran. The Engineering Economist, 23(5), 471-484. 